Article

\title{
Enhancing the Sustainability of a Location-Aware Service through Optimization
}

\section{Horng-Ren Tsai ${ }^{1}$ and Toly Chen ${ }^{2, *}$}

1 Department of Information Technology, Lingtung University, No. 1, Lingtung Rd, Taichung City 408, Taiwan; E-Mail: hrt@teamail.ltu.edu.tw

2 Department of Industrial Engineering and Systems Management, Feng Chia University, No. 100, Wenhua Rd, Taichung City 407, Taiwan

* Author to whom correspondence should be addressed; E-Mail: tolychen@ms37.hinet.net; Tel.: +886-4-2451-7250 (ext. 3645); Fax: +886-4-2451-0240.

External Editor: Marc A. Rosen

Received: 26 August 2014; in revised form: 9 December 2014 / Accepted: 15 December 2014 / Published: 18 December 2014

\begin{abstract}
A location-aware service (LAS) is an imperative topic in ambient intelligence; an LAS recommends suitable utilities to a user based on the user's location and context. However, current LASs have several problems, and most of these services do not last. This study proposes an optimization-based approach for enhancing the sustainability of an LAS. In this paper, problems related to optimizing an LAS system are presented. The distinct nature of an LAS optimization problem in comparison with traditional optimization problems is subsequently described. Existing methods applicable to solving an LAS optimization problem are also reviewed. The advantages and disadvantages of each method are then discussed as a motive for combining multiple optimization methods in this study, as illustrated by an example. Finally, opportunities and challenges faced by researchers in this field are presented.
\end{abstract}

Keywords: location-aware service (LAS); optimization; sustainability; ambient intelligence 


\section{Introduction}

A location-aware service (LAS), or location-based service, is a widely discussed topic in ambient intelligence [1-3]. An LAS is a special context-aware service that recommends suitable utilities to a user based on the user's location [4]. The main research fields of LAS include mobile commerce, human-computer interfaces, remote detection, and ubiquitous computing. Dialing an emergency number using a cell phone, package tracking systems, navigation systems, and mobile marketing are typical examples of LASs.

Park et al. [5] reported that providing LASs is a challenging task because of latency, limited display, and intermittent connectivity to the backend database. Nevertheless, according to Zickuhr [6], as of 2012, approximately three-quarters of smartphone owners have used LASs. Raper et al. [7] listed three emerging areas of LASs as location-based gaming, assistive technology, and location-based health applications. Kruger et al. [8] reported that location determining and situational responsiveness are particularly crucial to mobile guides, but are still far from perfect. Espeter and Raubal [9] recently considered personalization as one of the most vital developments of LASs; however, how to support multiple users simultaneously remains to be studied [10].

In summary, existing LASs demonstrate the following problems:

(1) There is no systematic procedure for designing a practicable LAS.

(2) Most LAS applications have not included cost-benefit analyses [11]. One reason is that massive government support is not focused on making profit. Another reason is the difficulty in collecting the relevant information on the client/user side. In addition, relating the final action of a user to the LAS provided is a difficult task. However, to ensure the sustainability of an LAS, these problems must be overcome to conduct a credible cost-benefit analysis.

(3) Most LASs are not always lasting; therefore, ongoing developments of new LASs may not be worthwhile.

(4) Most LAS applications can be modeled as human-system interaction processes of which human factors/ergonomics are an indispensable part and should be greatly emphasized.

An LAS system can resolve these problems and pursue sustainable development in the following manners (Figure 1): continuously updating the database, adding new features, and retiring uninteresting services; providing more options and flexibility; and improving the suitability for use. This involves multiple facets, and is a process that relies heavily on users' feedback and must evolve over time. In addition, according to Problem 3, this process can be considered a long-term optimization process, and some small-scale short-term optimization actions are undertaken at each time point for improving the LAS system. However, because enabling an LAS system to operate smoothly is a highly difficult task, most LAS systems have not been optimized. One possible reason is that some LAS systems must serve many people simultaneously [9]. The problem of optimizing LAS performance for multiple users is extremely complicated, even in the short term. In addition, the goal of an LAS is to meet the needs of users that are diverse and change over time; therefore, they cannot be fully quantified. 
Figure 1. A sustainable Location-aware service (LAS).

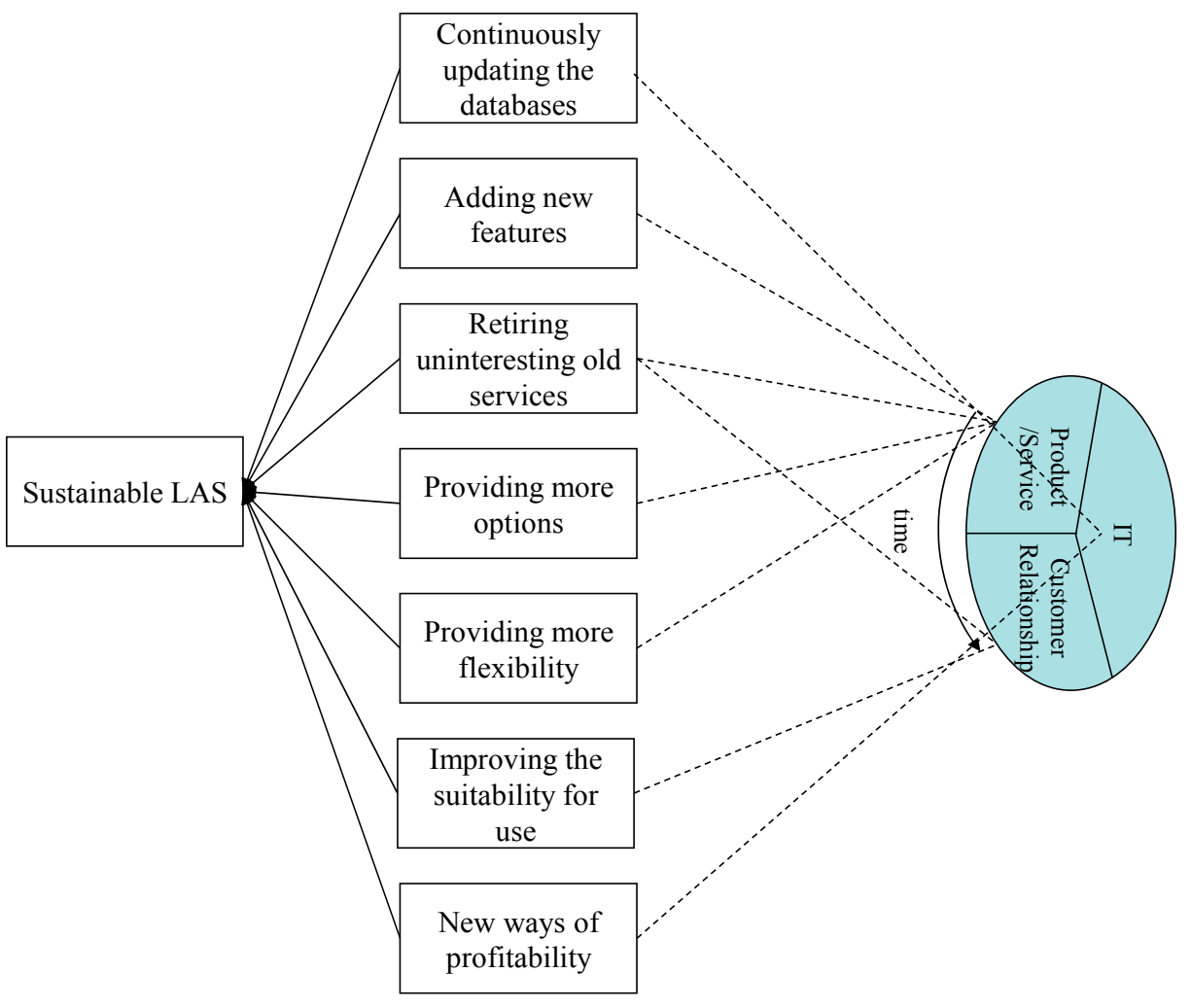

The objective of this study was to discuss problems related to optimizing an LAS system. First, the distinct characteristics of an LAS optimization problem compared with traditional optimization problems is described. The objectives and constraints faced when operating an LAS system are subsequently summarized into several categories. The solution space for the LAS optimization problem can be established based on these items. Subsequently, existing methods applicable to solving an LAS optimization problem are reviewed. The advantages and disadvantages of each method are also discussed, which motivated the combination of multiple optimization methods, as illustrated by an example. Finally, opportunities and challenges faced by researchers in this field are presented.

\section{Distinct Characteristics of an LAS Optimization Problem}

Optimizing an LAS is a controversial problem. Numerous LASs involve human decision-making processes, such as deciding whether to follow the results of an online restaurant recommendation system. However, human decision-making is not strictly optimizing in an economical and mathematical sense [12,13]. In addition, representing people's subjective feelings by using a simple scale, as performed in several other fields, is inappropriate [14]. Therefore, an LAS optimization problem cannot be resolved simply by applying heuristics.

Optimizing an LAS is also a difficult task. First, bulk information may need to be processed, which renders the optimization model extremely large. In addition, such data are dynamic and often incomplete [15], and this phenomenon poses a challenge to the adaptability and robustness of the optimization model. Furthermore, users' preferences for the recommended service are unclear, vague, inconsistent, and difficult to quantify. Setting a single objective function that is applicable to everyone is 
thus a difficult task $[9,16,17]$. In addition, cultural differences also considerably influence optimizing an LAS. For example, dietary preferences are crucial inputs to a restaurant recommendation LAS. However, dietary preferences are typically culturally specified and can convey different meanings in different social or cultural settings. This implies that the relationship among the variables in the optimization model may differ according to culture. Furthermore, data incompleteness is another problem. In most cases, users are unwilling or find it inconvenient to answer all the questions, for example, when in need of a distant emergency care. However, the system must still assist the user by making decisions based on incomplete information.

\section{LAS Optimization Problem}

\subsection{Objectives and Constraints}

Most LAS systems are configured as client-server systems [18]. The objectives and constraints on the client side, server side, or for the whole LAS system must be considered. On the client side, typical objectives include the average time for filling in a request, average time for receiving a response, average service level [15], average waiting time for the requested service, traversal time [11], suitability [16,19], recall rate, precision rate, and F1 metric. On the server side, the objectives include the required investment, number of app downloads, number of requested services, commission received, return on investment, and payback period. For the whole LAS system, the objectives include the number of successful recommendations and amount of purchases through the system. Essentially, the performance on the client side influences that on the server side. The performance of the whole LAS system depends on both sides (Figure 2).

Figure 2. Relationships among the objectives.

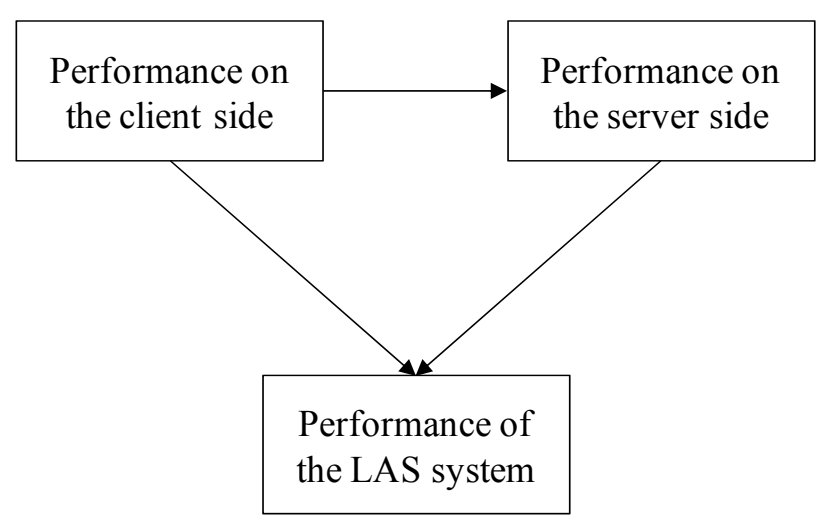

Rinner and Raubal [20] reported three spatiotemporal constraints on an LAS:

(1) Capability constraints: The location that can be reached by a user is limited by the user's transportation mode.

(2) Coupling constraints: In a group LAS, the location that may be reached by a user must be reachable to the other users.

(3) Authority constraints (i.e., the accessibility of a service location at different time intervals): The needs and preferences of a user are objectives of as well as constraints on an LAS system. 


\subsection{Solution Space}

In most LASs, only a few (or countable) alternatives are available, thus forming a discrete feasible region with limited solutions. For example, in a restaurant recommendation LAS, the number of restaurants that can be reached by a user within a certain period of time and are in accordance with the user's needs is only 10. However, these alternatives can be practiced using an infinite number of methods (i.e., infinite possible actions). In addition, the user can go to the recommended restaurant at different speeds via different paths. An optimization model can address either of the two problems, or both problems simultaneously. For example, the restaurant recommendation LAS can recommend a restaurant from several alternatives to a user, and subsequently determine the shortest path to the restaurant (i.e., transportation planning in advance; TPI) (Figure 3). In this approach, the traversal time to each restaurant is not considered in sorting the alternatives. Another method involves evaluating the shortest path to each restaurant, and then incorporating the evaluation results in making the recommendation (i.e., transportation planning afterwards; TPA) (Figure 4).

Figure 3. Transportation planning in advance.

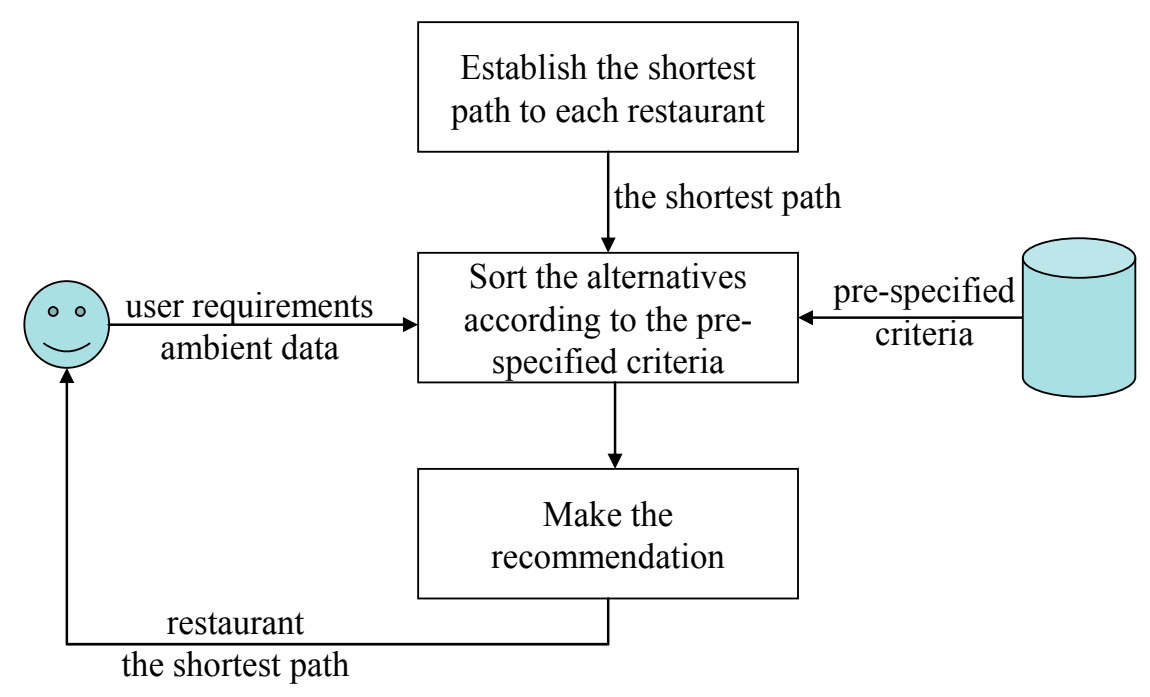

Figure 4. Transportation planning afterwards.

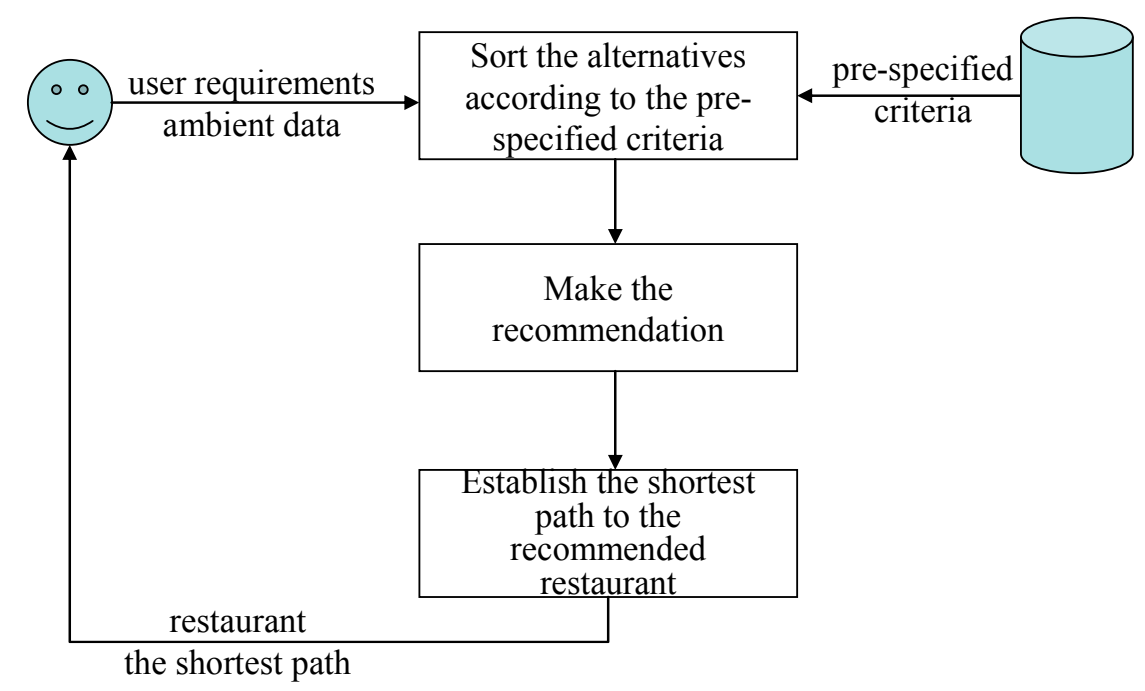


Methods that are suitable for problems comprising discrete feasible regions include the ordered weighted average (OWA) operator [20,21] and decision rules.

Another problem involves the similarity between two solutions. Some of the solutions also contain other solutions. However, these phenomena enable a flexible recommendation; nevertheless, they increase the complexity of decision making.

\section{Applicable Methods for Solving an LAS Optimization Problem}

Decision rules have been widely used for solving a location recommendation problem. For example, Mateo et al. [22] established a restaurant recommendation system that involves using fuzzy inference rules to process context information. Astrain et al. [23] established a fuzzy inference system for estimating the location of a user. The inputs to the fuzzy inference system were Wi-Fi signal strengths in specific zones, which were expressed in linguistic terms. The output from the fuzzy inference system associated the user with a specific zone. Savage et al. [24] designed a restaurant recommendation LAS system that processed a user's location, preferences, feelings, and transportation mode by using decision trees to make a recommendation. Decision rules are not self-optimizing, but rely on a systematic procedure for improving their performance. If decision rules are established/selected subjectively, then they should be adjusted if the outcome deviates from the reasoning result, or appended if they cannot be applied to a new case. Furthermore, decision rules should be reorganized periodically according to the most recent statistics to optimize their performance. One drawback of decision trees is that, occasionally, the existing rules cannot cover all cases if they were subjectively established/chosen. A systematic approach for establishing rules, such as using classification and regression trees, can be applied to solve this problem. Another problem involves the misclassification of cases, which was resolved by Savage et al. [24] by using a discrete hidden Markov model.

The second common practice involves optimizing (or improving) a prespecified criterion iteratively with experts' intervention. For example, Andrienko et al. [25] constructed a self-organizing map (SOM) for analyzing spatiotemporal patterns. The clustering results were interpreted by experts. The SOM was modified when outliers were observed. The process continues until only a few outliers remain.

The OWA operator is another technique often applied to multicriteria LAS optimization processes because of its ease of use. For example, Rinner and Raubal [20] designed a hotel recommendation service called Hotel Finder that recommends hotels to a user by considering the user's location, spatiotemporal constraints, and preferences. The performance of a restaurant in different aspects were aggregated through the OWA operator. However, for optimizing the performance, the design strategy of the OWA operator must be adjusted continuously. Another drawback of the OWA operator is that the utilities of some alternatives may be the same (i.e., ties). For overcoming this problem, several advanced OWA operators - such as the basic defuzzification distribution (BADD) OWA operator [21], additive neat BADD OWA operator [26], intuitionistic OWA operator [27], and most preferred OWA (MP-OWA) operator [28] - have been proposed in recent years. Table 1 shows a summary of these rules. 
Table 1. Various ordered weighted averages (OWA) operators.

\begin{tabular}{|c|c|c|}
\hline Operator & Formula & Variable Meanings \\
\hline & (1) Sort $\left\{x_{i j} \mid j=1 \sim K\right\}$ along $j$ to obtain & \multirow{7}{*}{$\begin{array}{ll}- & i \text { : alternative, } i=1 \sim N \\
- & j \text { : criterion, } j=1 \sim K \\
- & w_{j}: \text { weight of the } j \text {-th position, } \\
& w_{j}=f(N, j, \alpha) \\
\text { - } & x_{i j}: \text { performance of alternative } i \\
& \text { in attribute } j \\
\text { - } & U_{i}: \text { utility of alternative } i\end{array}$} \\
\hline & $\left\{y_{i j} \mid j=1 \sim K, y_{i j} \geq y_{i, j-1}\right\}$ for each $i$ & \\
\hline OWA & (2) $U_{i}=\sum_{j=1}^{n} w_{j} y_{i j}$ & \\
\hline & (3) Choose alternative $i$ that maximizes $U_{i}$ & \\
\hline BADD-OWA & (1) $U_{i}=\sum_{j=1}^{n} w_{i j} y_{i j}$; (2) $w_{i j}=y_{i j}^{\gamma} / \sum_{j=1}^{K} y_{i j}^{\gamma}$ & \\
\hline additive neat OWA & (1) $U_{i}=\sum_{j=1}^{n} w_{i j} y_{i j} ;$ (2) $w_{i j}=f\left(y_{i j}\right) / \sum_{j=1}^{K} f\left(y_{i j}\right)$ & \\
\hline MP-OWA & $\begin{array}{l}\text { (1) } S=\left\{S_{l} \mid l=1 \sim L\right\} \text { is a scale containing } L \\
\text { values to choose } \\
\text { (2) } w_{j}=\max _{l} N\left(x_{*_{j}}=S_{l}\right) / \sum_{j=1}^{K} \max _{l} N\left(x_{*_{j}}=S_{l}\right)\end{array}$ & \\
\hline
\end{tabular}

As mentioned previously, data incompleteness is an unavoidable problem that hinders the operation of an LAS. One method for resolving this problem involves considering only the dimensions with complete data. Ties are broken by considering the remaining dimensions without complete data. Some OWA operators can also address data incompleteness. For example, Herrera-Viedma et al. [29] proposed an iterative procedure for estimating the missing information in an expert's incomplete fuzzy preferences. The additive consistency OWA operator was subsequently proposed for sorting alternatives.

Mathematical programming is a traditional optimization method that has been applied to LAS optimization problems. Chen and $\mathrm{Wu}$ [30] formulated a problem of determining the just-in-time service location for a user as an integer-nonlinear programming (INLP) problem. Lin and Chen [11] also solved a biobjective fuzzy INLP (FINLP) problem to recommend a user a path for maximizing the timeliness of reaching a service location and minimizing the time remaining to reach the destination. However, the practical applicability of mathematical programming is limited because implementing this technique online is a difficult task.

In the literature, heuristics have been proposed for overcoming the difficulty associated with mathematical programming. Heuristics are more easily programmed, and can determine a near-optimal solution. For example, Chen and Huang [16] proposed a fuzzy Dijkstra algorithm for determining the just-in-time output location in a ubiquitous printing system. To further enhance the efficiency of solving the FINLP problem proposed by Lin and Chen [11], Chen [10] established a parallel processing scheme that considered multiple service locations simultaneously and solved the problem backward.

Applications of soft computing techniques are also observed in this field. By positioning a user indoors, Link et al. [17] matched the detected steps of the user onto the expected route by using sequence alignment algorithms that involve arranging sequences to identify regions of similarity in Bioinformatics, similar to the concept of dynamic programming. However, soft computing methods may be excessively complicated and time-consuming to be suitable for online applications.

Most LAS systems must serve many users simultaneously. One approach involves addressing these requests individually, which is more convenient in practice; however, resources can be allocated more 
effectively by considering multiple needs simultaneously to provide users with high-quality services. In addition, some users may belong to the same group; therefore, their needs can be met collectively. By contrast, Espeter and Raubal argued that instead of pursuing an optimal overall performance, focus should be placed on not sacrificing the utility of any user.

Figure 5 illustrates a summary of applicable methods in this field. Table 2 shows a summary of the advantages and disadvantages of these methods, which motivated the combination of multiple optimization methods in this study.

Figure 5. Methods applicable to a location-aware service (LAS) optimization problem.

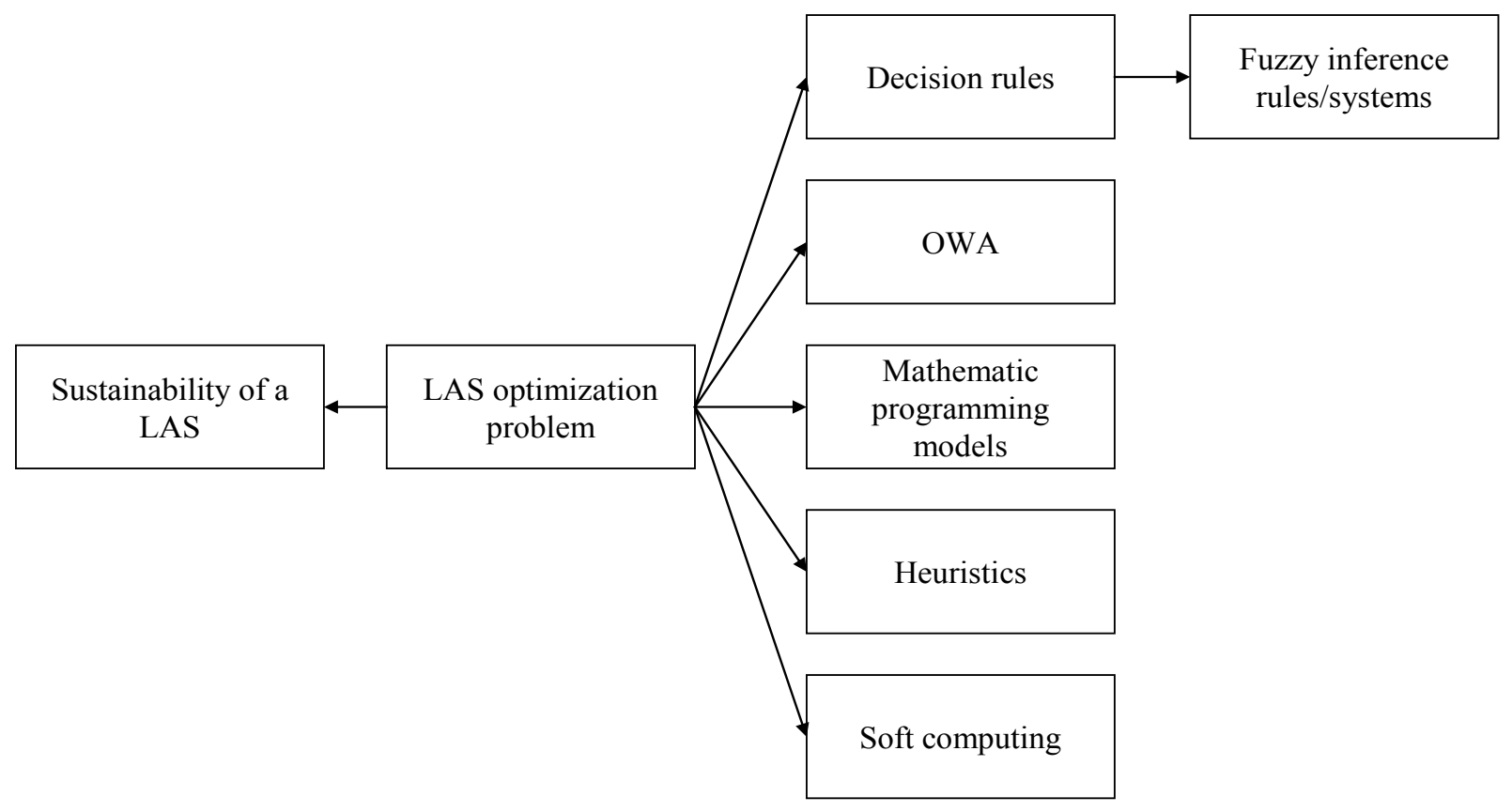

Table 2. Advantages and disadvantages of various optimization methods.

\begin{tabular}{|c|c|c|}
\hline $\begin{array}{c}\text { Optimization } \\
\text { Method }\end{array}$ & Advantages & Disadvantages \\
\hline $\begin{array}{l}\text { Decision } \\
\text { Rules }\end{array}$ & $\begin{array}{ll}\text { - } & \text { Easy to implement } \\
\text { - } & \text { Efficient }\end{array}$ & $\begin{array}{ll}\text { - } & \text { Need to be updated continuously } \\
\text { - } & \text { Often non-optimal }\end{array}$ \\
\hline $\begin{array}{l}\text { Interactive } \\
\text { Methods }\end{array}$ & $\begin{array}{ll}\text { - } & \text { Easy to communicate } \\
\text { - } & \text { Flexible } \\
\end{array}$ & - Often non-optimal \\
\hline OWA & $\begin{array}{ll} & \text { Consider the quality performance } \\
\text { - } & \text { Easy to implement }\end{array}$ & $\begin{array}{ll}\text { - } & \text { Subjective } \\
\text { - } & \text { Often non-optimal } \\
\end{array}$ \\
\hline $\begin{array}{l}\text { Mathematical } \\
\text { Programming }\end{array}$ & - Usually optimal & $\begin{array}{l}\text { - } \quad \text { Can consider only small-scale problems } \\
\text { - } \quad \text { Not compatible with other modules }\end{array}$ \\
\hline Heuristics & $\begin{array}{ll}\text { - } & \text { Easy to program } \\
\text { - } & \text { Easy to implement } \\
\text { - } & \text { Efficient } \\
\end{array}$ & $\begin{array}{l}\text { - } \quad \text { Solutions may be far from optimal } \\
\text { - }\end{array}$ \\
\hline $\begin{array}{c}\text { Soft } \\
\text { Computing } \\
\end{array}$ & $\begin{array}{ll}\text { - } & \text { Optimal or near-optimal solution } \\
\text { - } & \text { Compatible with other modules } \\
\end{array}$ & $\begin{array}{ll}\text { - } & \text { Complicate } \\
\text { - } & \text { May be time-consuming } \\
\end{array}$ \\
\hline
\end{tabular}




\section{Example of Combining Different Optimization Methods}

Figure 6 shows an example in which a user travels from $S$ (the current location) to $D$ (destination). On the way to the destination, the user requests a service from one of 10 possible service locations (indicated by $A-J$, respectively) and requires a recommendation from the LAS system. Table 3 shows a summary of the user's requirements and conditions of the service locations.

Figure 6. Example of combining different optimization methods.

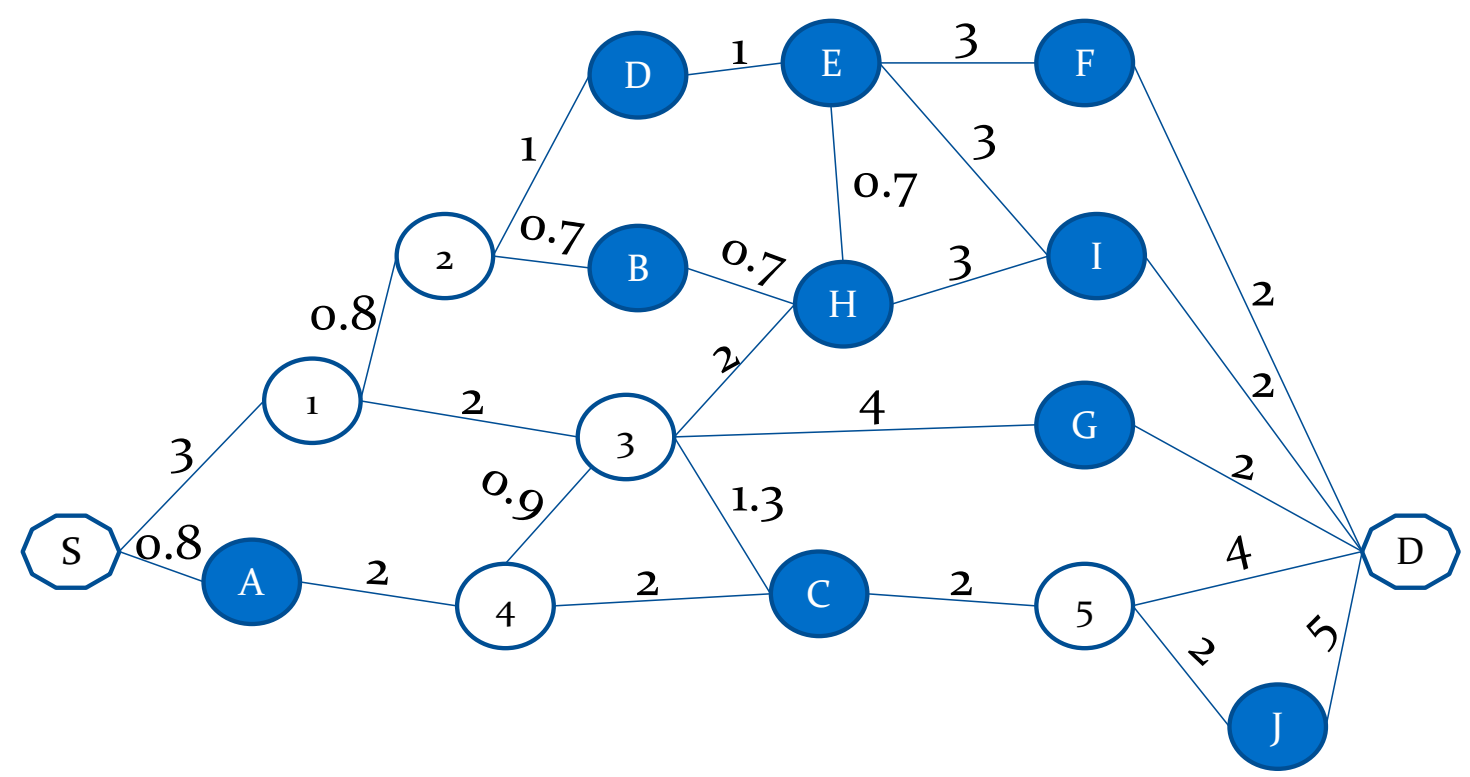

Table 3. Requirements of the user and conditions of the service locations.

\begin{tabular}{ccccc}
\hline Entity & Service Fee (NTD) & $\begin{array}{c}\text { Estimated Waiting } \\
\text { Time (min) }\end{array}$ & Decoration & Space \\
\hline User & $\leq 1500$ & $\leq 30$ & Acceptable & Spacious \\
\hline A & 2300 & 20 & Luxurious & Spacious \\
\hline B & 1200 & 50 & Acceptable & Moderate \\
\hline C & 1780 & 25 & Acceptable & Spacious \\
\hline D & 550 & 90 & Acceptable & Narrow \\
\hline E & 1800 & 40 & Luxurious & Narrow \\
\hline F & 1320 & 65 & Acceptable & Moderate \\
\hline G & 750 & 20 & Acceptable & Narrow \\
\hline H & 3500 & 30 & Luxurious & Spacious \\
\hline I & 660 & 75 & Acceptable & Spacious \\
\hline J & 1100 & 85 & Luxurious & Spacious \\
\hline
\end{tabular}

The objective function is used to maximize the average suitability $\bar{S}$ :

$$
\operatorname{Max} \bar{S}
$$

Based on the user's requirements, the formulae for evaluating the suitability are as follows: 
(Service Fee)

$$
S_{1}=\left\{\begin{array}{ccc}
1 & \text { if } & \text { service fee }<1500 \\
\frac{2000-\text { service fee }}{500} & \text { if } & 1500 \leq \text { service fee }<2000 \\
0 & \text { otherwise } &
\end{array}\right.
$$

(Estimated Waiting Time)

$$
S_{2}=\left\{\begin{array}{ccc}
1 & \text { if } & \text { estimated waiting time }<30 \\
\frac{60-\text { estimated waiting time }}{30} & \text { if } \quad 30 \leq \text { estimated waiting time }<60 \\
0 & \text { otherwise }
\end{array}\right.
$$

(Decoration)

$$
S_{3}=\left\{\begin{array}{l}
1 \quad \text { if } \quad \text { decoration }=\text { "acceptable" or "luxurious" } \\
0 \text { otherwise }
\end{array}\right.
$$

(Space)

$$
S_{4}=\left\{\begin{array}{l}
1 \quad \text { if } \quad \text { space }=\text { "spacious" } \\
0.5 \quad \text { if } \quad \text { space }=\text { "moderate" } \\
0 \text { otherwise }
\end{array}\right.
$$

The suitability of the traversal time can also be evaluated as follows:

(Traversal Time)

$$
S_{5}=\left\{\begin{array}{cc}
1-\frac{\text { traversal time }}{30} & \text { if } \quad \text { traversal time } \leq 30 \\
0 & \text { otherwise }
\end{array}\right.
$$

where the upper time limit, $30 \mathrm{~min}$, is established by considering the target of the estimated waiting time in (3).

To apply the TPI method, the shortest path to each service location is determined by solving the following INLP problem:

$$
\begin{gathered}
\operatorname{Min}_{n} \\
d_{i} \leq d_{j}+l_{j i}, i=1 \sim n ; j<i ; l_{j i} \neq \infty \\
d_{i}=\sum_{j<i, l_{j i} \neq \infty} x_{j i}\left(d_{j}+l_{j i}\right), i=1 \sim n \\
\sum_{j<i, l_{j i} \neq \infty} x_{j i}=1, i=1 \sim n \\
x_{j i} \in\{0,1\}, i=1 \sim n ; j<i ; l_{j i} \neq \infty
\end{gathered}
$$

where $n$ is the number of nodes in the traffic network. The length of the path connecting nodes $i$ and $j$ is $l_{i j} ; i, j=1 \sim n ; i \neq j ; l_{i j}=\infty$ if there is no connection between the two nodes. If nodes are numbered from 
the start point to the destination, then the start point and destination are nodes 1 and $n$, respectively. In addition, no back path is allowed (i.e., $l_{i j}=\infty$ if $i>j$ ). The shortest distance from the start point to node $i$ is represented by $d_{i}$. Obviously, $d_{1}=0$ and $d_{n}=\max _{i} d_{i}$. Table 4 shows the results.

Table 4. Shortest path to each service location.

\begin{tabular}{ccc}
\hline Service Location & Shortest Path & Traversal Time (min) \\
\hline A & S->A & 0.8 \\
\hline B & S->1->2->B & 4.5 \\
\hline C & S->A->4->C & 4.8 \\
\hline D & S->1->2->D & 4.8 \\
\hline E & S->1->2->D->E & 5.8 \\
\hline F & S->1->2->D->E->F & 8.8 \\
\hline G & S->1->3->G & 9 \\
\hline H & S->1->2->B $>$ H & 5.2 \\
\hline I & S->1->2->B->H->I & 8.2 \\
\hline J & S->A->4->C $->5->$ J \\
\hline
\end{tabular}

The average satisfaction level of every service location along each dimension is subsequently evaluated, and Table 5 shows a summary of the results. Service location $C$ obtains the highest average satisfaction level. By contrast, if the TPA method is applied, the traversal time is not considered when reasoning, and the most suitable service location is $G$. The shortest path to $G$ is $S->1->3->G$.

Table 5. Satisfaction level of each service location.

\begin{tabular}{cccccccc}
\hline Service Location & $\boldsymbol{S}_{\mathbf{1}}$ & $\boldsymbol{S}_{\mathbf{2}}$ & $\boldsymbol{S}_{\mathbf{3}}$ & $\boldsymbol{S}_{\mathbf{4}}$ & $\boldsymbol{S}_{\mathbf{5}}$ & $\overline{\boldsymbol{S}}$ (TPI) & $\overline{\boldsymbol{S}}$ (TPA) \\
\hline $\mathrm{A}$ & 0 & 1 & 1 & 1 & 0.97 & 0.79 & 0.75 \\
\hline $\mathrm{B}$ & 1 & 0.33 & 1 & 0.5 & 0.85 & 0.74 & 0.71 \\
\hline $\mathrm{C}$ & 0.44 & 1 & 1 & 1 & 0.84 & 0.86 & 0.86 \\
\hline $\mathrm{D}$ & 1 & 0 & 1 & 0 & 0.84 & 0.57 & 0.50 \\
\hline $\mathrm{E}$ & 0.4 & 0.67 & 1 & 0 & 0.81 & 0.57 & 0.52 \\
\hline $\mathrm{F}$ & 1 & 0 & 1 & 0.5 & 0.71 & 0.64 & 0.63 \\
\hline $\mathrm{G}$ & 1 & 1 & 1 & 0.5 & 0.70 & 0.84 & 0.88 \\
\hline $\mathrm{H}$ & 0 & 1 & 1 & 1 & 0.83 & 0.77 & 0.75 \\
\hline $\mathrm{I}$ & 1 & 0 & 1 & 1 & 0.73 & 0.75 & 0.75 \\
\hline $\mathrm{J}$ & 1 & 0 & 1 & 1 & 0.71 & 0.74 & 0.75 \\
\hline
\end{tabular}

For applying the OWA operator, the satisfaction levels along the five (or four) dimensions are sorted, as shown in Table 6, in which $S_{(i)}$ indicates the $i$-th highest satisfaction level, $i=1-5$ (or 4 ). The "moderately optimistic" decision strategy is then adopted. The ordered weighted average satisfaction level of each service location is calculated, and Table 6 also shows the results. As shown in Table 6, the optimal service location obtained using the TPI method is $C$, whereas that obtained using the TPA method is $A$. The results are slightly different from those obtained when the average satisfaction level is maximized. This is a property vital to the flexibility of an LAS. 
Table 6. The sorted satisfaction levels.

\begin{tabular}{cccccccc}
\hline Service Location & $\boldsymbol{S}_{(\mathbf{1})}$ & $\boldsymbol{S}_{(\mathbf{2})}$ & $\boldsymbol{S}_{(\mathbf{3})}$ & $\boldsymbol{S}_{(\mathbf{4})}$ & $\boldsymbol{S}_{(\mathbf{5})}$ & OWA (TPI) & OWA (TPA) \\
\hline A & 1 & 1 & 1 & 0.97 & 0 & 0.93 & 1.00 \\
\hline B & 1 & 1 & 0.85 & 0.5 & 0.33 & 0.90 & 0.94 \\
\hline C & 1 & 1 & 1 & 0.84 & 0.44 & 0.95 & 0.99 \\
\hline D & 1 & 1 & 0.84 & 0 & 0 & 0.84 & 0.90 \\
\hline E & 1 & 0.81 & 0.67 & 0.4 & 0 & 0.83 & 0.89 \\
\hline F & 1 & 1 & 0.71 & 0.5 & 0 & 0.87 & 0.93 \\
\hline G & 1 & 1 & 1 & 0.70 & 0.5 & 0.94 & 0.98 \\
\hline H & 1 & 1 & 1 & 0.83 & 0 & 0.92 & 0.99 \\
\hline I & 1 & 1 & 1 & 0.73 & 0 & 0.91 & 0.98 \\
\hline J & 1 & 1 & 1 & 0.71 & 0 & 0.91 & 0.98 \\
\hline
\end{tabular}

\section{Opportunities and Challenges}

As mentioned previously, combining multiple optimization methods facilitates the process of improving the effectiveness and flexibility of an LAS system, and should be studied further in the future.

Improving the precision of positioning a user is another critical problem in the sustainability of an LAS [31]. Several attempts have recently been made in this regard. Some advanced technologies have been proposed for indoor user positioning, as summarized in Table 7. Regarding outdoor user positioning, Japanese engineers are currently initiating the first commercial, nationwide, centimeter-scale satellite positioning technology by precisely correcting GPS signal errors [32]. Once successful, user positioning is expected to be highly precise, thereby reducing the possibility of misleading a user. The popularity of wearable devices also presents opportunities; for example, an LAS system can "see" rather than "guess" the location of a user through Google Glass worn by the user.

Table 7. Advanced technologies for indoor user positioning.

\begin{tabular}{|c|c|c|c|}
\hline Reference & Method & Description & Results \\
\hline $\begin{array}{l}\text { Astrain } \\
\text { et al. [23] }\end{array}$ & $\begin{array}{l}\text { Fuzzy inference } \\
\text { system }\end{array}$ & $\begin{array}{l}\text { Inputs to the fuzzy inference system are Wi-Fi } \\
\text { signal strengths in specific zones; the output from } \\
\text { the fuzzy inference system is the membership } \\
\text { that a user is in a specific zone. }\end{array}$ & $\begin{array}{l}\text { a correct recognition } \\
\text { rate from } 84 \% \text { to } 90 \%\end{array}$ \\
\hline $\begin{array}{l}\text { Link } \\
\text { et al. [17] }\end{array}$ & $\begin{array}{l}\text { Map-based } \\
\text { indoor } \\
\text { navigation }\end{array}$ & $\begin{array}{l}\text { The detected steps of a user is mapped } \\
\text { onto the expected route using sequence } \\
\text { alignment algorithms. }\end{array}$ & $\begin{array}{l}\text { able to guide a user } \\
\text { turn-by-turn }\end{array}$ \\
\hline $\begin{array}{l}\text { Ruiz-Ruiz } \\
\text { et al. [33] }\end{array}$ & $\begin{array}{l}\text { Vision-enhanced } \\
\text { multisensor LBS }\end{array}$ & $\begin{array}{l}\text { A coarse-grained estimation is first obtained } \\
\text { based on WiFi signals, digital compasses, and } \\
\text { built-in accelerometers. Then, the position of a } \\
\text { user is determined using fingerprinting methods, } \\
\text { probabilistic techniques, and motion estimators. }\end{array}$ & $\begin{array}{l}\text { - the positioning error } \\
\leq 15 \mathrm{~cm} \\
\text { - the response time } \\
\leq 0.5 \mathrm{~s}\end{array}$ \\
\hline $\begin{array}{l}\text { Sakamoto } \\
\text { et al. [34] }\end{array}$ & Doppler IMES & $\begin{array}{l}\text { The position and orientation of a user with a } \\
\text { receiver are estimated according to the Doppler } \\
\text { shifts produced by moving the receiver antenna } \\
\text { with two or more IMES transmitters. }\end{array}$ & $\begin{array}{l}\text { - the positioning error } \\
\leq \text { a few decimeters } \\
\text { - the orientation error } \\
\leq \text { a few degrees }\end{array}$ \\
\hline
\end{tabular}


LASs for special groups, such as the blind, vision impaired, and the elderly, have not yet been designed. In this regard, Gallagher et al. [35] proposed several criteria-including positioning accuracy, robustness, seamless integration with the environment, and the nature of information to be provided - for evaluating the success of an LAS for such groups.

Several indoor LAS systems guide a user to the location containing commodities in which the user is interested. Popular and unpopular routes can be discriminated after collecting the data of a sufficient number of users. Based on the results, the showcases of commodities can be rearranged, for example, to shorten the distance that a user must travel. The contribution (e.g., number of visits or purchases) by a user can also be considered by minimizing the weighted sum of distances instead, in which the weight of a route is equal to the average contribution of users that have traveled along the route.

Another trend to be expected is increased cooperation among different service locations through a common LAS system. However, this is based on the premise that these service locations are willing to cooperate and provide more operating information, such as availability and the average waiting time, to the LAS system.

\section{Acknowledgments}

This work was partially supported by the Ministry of Science and Technology of Taiwan under Grant No. MOST 103-2221-E-035-043-MY3.

\section{Author Contributions}

Prof. Chen proposed the methodology and wrote most of the content of this paper. Dr. Tsai is responsible for the design of the experiment detailed in Section 5, as well as the analysis of the experimental results. Dr. Tsai also helped revise the main text, and arranged the English editing service of this paper.

\section{Conflicts of Interest}

The authors declare no conflict of interest.

\section{References}

1. Cook, D.J.; Augusto, J.C.; Jakkula, V.R. Ambient intelligence: Technologies, applications, and opportunities. Pervasive Mob. Comput. 2009, 5, 277-298.

2. Ducatel, K.; Bogdanowicz, M.; Scapolo, F.; Leijten, J.; Burgelman, J.-C. Scenarios for Ambient Intelligence in 2010; European Commission: Brussels, Belgium, 2001.

3. Sadri, F. Ambient intelligence: A survey. ACM Comput. Surv. 2011, 44, doi:10.1145/1978802.1978815.

4. Dey, A.K. Understanding and using context. Pers. Ubiquitous Comput. 2001, 5, 4-7.

5. Park, M.-H.; Hong, J.-H.; Cho, S.-B. Location-Based Recommendation System Using Bayesian User's Preference Model in Mobile Devices. In Ubiquitous Intelligence and Computing; Indulska, J., Ma, J., Yang, L., Ungerer, T., Cao, J., Eds.; Springer: Berlin/Heidelberg, Germany, 2007; pp. 1130-1139. 
6. Zickuhr, K. Three-quarters of smartphone owners use location-based services. Available online: http://www.ris.org/uploadi/editor/1344244410PIP_Location_based_services_2012_Report.pdf (accessed on 16 December 2014).

7. Raper, J.; Gartner, G.; Karimi, H.; Rizos, C. Applications of location-based services: A selected review. J. Locat. Based Serv. 2007, 1, 89-111.

8. Krüger, A.; Baus, J.; Heckmann, D.; Kruppa, M.; Wasinger, R. Adaptive Mobile Guides. In The Adaptive Web; Brusilovsky, P., Kobsa, A., Nejdl, W., Eds.; Springer: Berlin/Heidelberg, 2007; pp. 521-549.

9. Espeter, M.; Raubal, M. Location-based decision support for user groups. J. Locat. Based Serv. 2009, 3, 165-187.

10. Chen, T. A fuzzy parallel processing scheme for enhancing the effectiveness of a dynamic just-in-time location-aware service system. Entropy 2014, 16, 2001-2022.

11. Lin, Y.-C.; Chen, T. A bi-objective fuzzy integer-nonlinear programming approach for creating an intelligent location-aware service. J. Appl. Math. 2013, doi:10.1155/2013/423415.

12. Cesta, A.; Oddi, A.; Smith, S. A Constraint-Based Method for Project Scheduling with Time Windows. J. Heuristics 2002, 8, 109-136.

13. Simon, H. A behavioral model of rational choice. Q. J. Econ. 1995, 69, 99-118.

14. Huang, D.; Chen, T.; Wang, M.-J.J. A fuzzy set approach for event tree analysis. Fuzzy Sets Syst. 2001, 118, 153-165.

15. Kotsakis, E.; Ketselidis, M. Modeling personalized and context sensitive behavior for location aware services by employing fuzzy logic. Available online: http:/www.wseas.us/e-library/conferences/ crete2002/papers/444-719.pdf (accessed on 16 December 2014).

16. Chen, T.; Huang, M. Establishing a just-in-time and ubiquitous output system. Int. J. Ambient Comput. Intell. 2013, 5, 32-43.

17. Link, J.Á.B.; Smith, P.; Viol, N.; Wehrle, K. Accurate map-based indoor navigation on the mobile. J. Locat. Based Serv. 2013, 7, 23-43.

18. Coronato, A.; de Pietro, G. Middleware mechanisms for supporting multimodal interactions in smart environments. Comput. Commun. 2008, 31, 4242-4247.

19. Malczewski, J. GIS and Multicriteria Decision Analysis; Wiley: New York, NY, USA, 1999.

20. Rinner, C.; Raubal, M. Personalized multi-criteria decision strategies in location based decision support. J. Geogr. Inf. Sci. 2004, 10, 149-156.

21. Yager, R.R. Families of OWA operators. Fuzzy Sets Syst. 1993, 59, 125-148.

22. Mateo, R.; Lee, M.; Joo, S.-C.; Lee, J. Location-Aware Data Mining for Mobile Users Based on Neuro-fuzzy System. In Fuzzy Systems and Knowledge Discovery; Wang, L., Jiao, L., Shi, G., Li, X., Liu, J., Eds.; Springer: Berlin/Heidelberg, Germany, 2006; pp. 1269-1278.

23. Astrain, J.J.; Villadangos, J.; Garitagoitia, J.R.; de Mendívil, J.R.G.; Cholvi, V. Fuzzy location and tracking on wireless networks. In Proceedings of the 4th ACM International Workshop on Mobility Management and Wireless Access, Torremolinos, Spain, 2-6 October 2006; ACM: New York, NY, USA, 2006; pp. 84-91.

24. Saiph Savage, N.; Baranski, M.; Elva Chavez, N.; Höllerer, T. I'm Feeling LoCo: A Location Based Context Aware Recommendation System. In Advances in Location-Based Services; Gartner, G., Ortag, F., Eds.; Springer: Berlin/Heidelberg, Germany, 2012; pp. 37-54. 
25. Andrienko, G.; Andrienko, N.; Bak, P.; Bremm, S.; Keim, D.; von Landesberger, T.; Pölitz, C.; Schreck, T. A framework for using self-organising maps to analyse spatio-temporal patterns, exemplified by analysis of mobile phone usage. J. Locat. Based Serv. 2010, 4, 200-221.

26. Liu, $\mathrm{X}$. The orness measures for two compound quasiarithmetic mean aggregation operators. Int. J. Approx. Reason. 2010, 51, 305-334.

27. Mitchell, H.B. An intuitionistic OWA operator. Int. J. Uncertain. Fuzziness Knowl. Based Syst. 2004, 12, 843-860.

28. Emrouznejad, A. MP-OWA: the most preferred OWA operator. Knowl. Based Syst. 2008, 21, 847-851.

29. Herrera-Viedma, E.; Chiclana, F.; Herrera, F.; Alonso, S. Group decision-making model with incomplete fuzzy preference relations based on additive consistency. IEEE Trans. Syst. Man Cybern. 2007, 37, 176-789.

30. Chen, T.; Wu, H.-C. Finding the just-in-time service location and path in a ubiquitous service network. Int. J. Internet Manuf. Serv. 2013, 3, 137-147.

31. Curran, K.; Furey, E.; Lunney, T.; Santos, J.; Woods, D.; Mc Caughey, A. An evaluation of indoor location determination technologies. J. Locat. Based Serv. 2011, 5, 61-78.

32. Boyd, J. Japan's plan for centimeter-resolution GPS. Available online: http://spectrum.ieee.org/ aerospace/satellites/japans-plan-for-centimeterresolution-gps (accessed on 16 December 2014).

33. Ruiz-Ruiz, A.J.; Canovas, O.; Lopez-de-Teruel, P.E. A vision-enhanced multisensor LBS suitable for augmented reality applications. J. Locat. Based Serv. 2013, 7, 145-164.

34. Sakamoto, Y.; Ebinuma, T.; Fujii, K.; Sugano, S. Doppler pose estimation using multiple IMES transmitters for indoor localisation. J. Locat. Based Serv. 2014, 8, 36-53.

35. Gallagher, T.; Wise, E.; Yam, H.C.; Li, B.; Ramsey-Stewart, E.; Dempster, A.G.; Rizos, C. Indoor navigation for people who are blind or vision impaired: Where are we and where are we going? J. Locat. Based Serv. 2014, 8, 54-73.

(C) 2014 by the authors; licensee MDPI, Basel, Switzerland. This article is an open access article distributed under the terms and conditions of the Creative Commons Attribution license (http://creativecommons.org/licenses/by/4.0/). 